\title{
A SCO-BASED TOWER CRANE SYSTEM FOR PREFABRICATION CONSTRUCTION
}

\author{
Diandian LIU ${ }^{1 *}$, Weisheng $\mathrm{LU}^{2}$, Yuhan $\mathrm{NIU}^{3}$ and Hongdi WANG ${ }^{4}$
}

\begin{abstract}
Prefabrication construction has been increasingly applied to the construction industry. Automation and intelligentization of construction site and construction objects has become the fore for the development of the prefabrication construction. In this study, a SCO-based tower crane system, as the core resource site on the critical path of prefabrication construction, is proposed to make the cranes more intelligent and efficient. A set of smart units are applied to the tower cranes and prefabricated components to make them into Smart Construction Objects (SCOs), enabling the functions of awareness, communicativeness and autonomy. The smart tower crane could "talk" with prefabrication components through sensors and real-time wireless connections. A system operation flow is developed for fetching and placing target components. The SCO-based tower crane system can provide the operation instruments, real-time traceability of the components, and necessary warning. The system is being tested in a pilot project, which is delivered through BIM and prefabrication construction. It is envisaged that the SCO-based tower crane system could significantly improve the safety performance and operation efficiency of the tower crane operations in prefabrication construction.
\end{abstract}

Keywords: prefabrication construction, SCO, tower crane, safety.

\footnotetext{
1* Diandian Liu

Corresponding author, Department of Real Estate and Construction, The University of Hong Kong, Hong Kong E-mail: liudd@connect.hku.hk

2 Weisheng Lu

Department of Real Estate and Construction, The University of Hong Kong

3 Yuhan Niu

Department of Real Estate and Construction, The University of Hong Kong

${ }^{4}$ Hongdi Wang

Department of Real Estate and Construction, The University of Hong Kong
} 


\section{Background}

Prefabrication is hallmark development of the industrialization of the construction industry. Different from traditional cast in-situ method, precast components are produced and tested in the factory, before they are assembly on-site. Prefabrication is widely perceived as a superior construction technology to traditional construction method in aspects such as including the improvement in environmental impacts through reduction in waste and $\mathrm{dust}^{[1]}$, the increased worker safety through reduced exposures to hazardous operations ${ }^{[2]}$, and the increment in whole-life performance and profitability ${ }^{[3]}$.

Due to its merits, prefabrication has been adopted in Hong Kong for more than two decades, mostly in in public housing projects ${ }^{[1]}$. In 2002, the precast components accounted for approximately $17 \%$ of the total concrete volume used in public housing projects ${ }^{[4]}$. The precast elements cover a wide range of construction elements including facades, staircases, parapets, partition walls, semi-precast slabs and, more recently, volumetric precast bathrooms and kitchens ${ }^{[2]}$. The advancement of prefabrication techniques has contributed significantly to a dense urban environment like Hong Kong, economically and environmentally ${ }^{[1]}$.

However, problems associated with the prefabrication construction are also reported. For example, high transportation cost has led to that overall prefabrication construction around $2 \%$ more expensive than using traditional technologies. It requires more carnage. When working with large amount of on-site prefabrication work, installation is often complicated especially when working under very congested floor layout at a high altitude ${ }^{[5]}$. Although innovation in techniques has improved the prefabrication construction ${ }^{[1]}$, the innovations mainly focus on the casting technique. It is desired that prefabrication could be improved by continuously developing innovative technologies such as automation and robotics.

To improve the construction by the means of automation has been proposed since decades $\mathrm{ago}^{[6]}$. Using robots to replace existing labor work and existing construction machinery is the main trend. There are robots like mobile crane that are designed for brick-laying and masonry work ${ }^{[7]}$. Using Contour Crafting (CC) system provides a way to fabricate a whole piece of hollow concrete structure on site by automatic computer control ${ }^{[8]}$. There are also breakthrough technologies for prefabrication construction. For example, a gantry is augmented with robotic intelligence to automatically assemble prefabricated component on site ${ }^{[9]}$, although it is designed for low-rise buildings.

Putting robots onsite as "helpers" for construction work might be a way to drive the technological development in the construction industry. Alternatively, to augment the existing on-site construction machinery and equipment with "smartness" for conducting traditional work might be another way without radical change in routines. In this study, a framework to develop a smart tower crane system is proposed to assist the on-site prefabrication construction work. Based on the concept of Smart Construction Objects (SCOs), the tower crane and prefabricated components in this system are augmented with the ability to sense, communicate and act autonomously. The remainder of the paper comprises six sections. Section 2 reviews the concept of SCO and defines the properties of SCOs in the smart tower crane system. Section 3 elaborates the rationale for setting up a digitized 3D site to support the system. Section 4 describes three components in the smart unit. A workflow of the system is introduced in Section 5. Section 6 
discusses the prospects and future research areas presented by the smart tower crane system, and conclusions are drawn in Section 7.

\section{SCO and smart crane system}

To meet the challenge in construction industry, Smart Construction Object (SCO) is introduced as a way to embed "intelligence" into construction recourses in order to assist construction management. A SCO is proposed as a step towards the ubiquitous computing in the construction context $^{[10]}$. In earlier study of Niu et al ${ }^{[10]}$, SCOs are defined as follows:

"Construction resources (e.g. machinery, tools, device, materials, components, and even temporary or permanent structures) that are made "smart" by augmenting them with sensing, processing and communication abilities so that they have autonomy and awareness, and can interact with the vicinity to enable better decision-making."

The smart tower crane system is one application example of SCOs, where traditional tower cranes and prefabricated components are augmented into SCOs. The sensing ability of SCO is addressed by awareness, which enables the prefabricated components to sense their real-time locations. Besides, by applying the communicativeness, a connection could be established between prefabricated components and the smart crane. Through the connection, prefabricated component could exchange information with the smart crane including the real-time coordinates, destination coordinates, and other geometric parameters. Based on the information captured by and transmitted from the smart prefabricated components, the smart tower crane could fetch and relocate these components with autonomy.

\section{Smart Unit}

To obtain the awareness, communicativeness and autonomy as described for SCOs, each of the prefabricated component and the crane are augmented with a smart unit. The core components of the smart unit are the location tracking module, the microcontroller, and the Bluetooth module.

\subsection{Location tracking module}

The awareness to sense real-time locations is achieved by the location tracking module in the smart Unit. A Global Positioning System (GPS) tracker and an Inertial Measurement Unit (IMU) work complementarily as the location tracking module for the smart tower crane system.

The GPS has been widely used in navigation and surveying application due to its capability to provide a 24-hour worldwide positioning service at a relatively low cost ${ }^{[11]}$. Relying signals from on the satellites, the accuracy of GPS has been made possible in a 10-meter level of chang ${ }^{[12]}$. Although the accuracy is comparatively high for road transportation positioning, it is still not enough for positioning of single building component. Thus a more precise positioning system for short distance is needed to help calibrate the result given by GPS system. Moreover, GPS may suffer from signal masking and multipath errors in area shielded by dense buildings or trees ${ }^{[11]}$. Hong Kong Island is typical city canyon area where only around $50 \%$ of the test area is receptive of adequate GPS signals in the study of $\mathrm{Lu}$ et $\mathrm{al}^{[11]}$. Therefore, GPS system alone is not enough for location tracking in the smart tower crane system.

Not like GPS that relies on satellites for positioning, an IMU is self-contained and it requires no external motion signals for positioning ${ }^{[11]}$. The IMU is reliable and stable while navigating 
under conditions of external disturbance ${ }^{[13]}$. The IMU consists of a gyroscope to sense angular rates, an accelerometer to sense acceleration and other sensors such as the magnetic sensor so that data from separate sensors could fuse into a single, optimum estimation ${ }^{[14]}$. After the acceleration of gravity is subtracted, the remaining accelerations would then be double integrated over time to determine the displacement of the IMU relative to a known starting point ${ }^{[15]}$. Since location tracking using IMU is based on integration against time of movement, even a small change of distance can be calculated. Thus IMU could offset the accuracy problem of GPS. On the other hand, with the increase of tracking time and distance, the IMU will suffer from drifting problem by integration ${ }^{[1][14][16][17]}$. The tracked locations may deviate from the real-time locations over time if IMU is used alone. Thus IMU is usually used with other sensors or systems, such as the optical navigation sensor ${ }^{[17]}$, for navigation and positioning purpose. Therefore, for the smart tower crane system, GPS is needed to calibrate the IMU result at regular time interval.

\subsection{Microcontroller}

The microcontroller is vitally important for realizing autonomous control. The application of microcontroller is widely adopted in autonomous robot control ${ }^{[18][19]}$. Likewise, acting like the 'brain' in every SCO, the microcontroller centrally manages the sensors, communicating devices, and the actuators in the Auto-In system. Data generated from the location tracking module would be compiled and interpreted by the microcontroller before communication. Besides, in traditional construction process, the motion of jib, trolley and hoisting rope of the tower crane are manually controlled by the operator. In the smart crane system, the motions of these components will be guided by instructions sent from the microcontroller, which are calculated and provided by the algorithms programmed inside.

\subsection{Communication module}

Communicativeness of SCOs is achieved by the communication module in the smart unit. Bluetooth is chosen for the smart tower crane system. Compared to other wireless communication technologies, Bluetooth is preferred because low-energy Bluetooth could perform lower power consumption ${ }^{[20]}$. It usually takes no less than one month for prefabricated components to be the manufactured, delivered and installation on-site. In the Hong Kong-Shenzhen cross-board cooperation for prefabrication construction, the transportation of prefabricated components may take longer time. Most wireless connection modules such as Wi-Fi module may largely consume the battery before the on-site operation. Comparatively, the low-power Bluetooth may support the smart prefabricated components for longer duration up to 6 months. Meanwhile, depending on the power class of the device, the typical working distance of Bluetooth ranges from $10 \mathrm{~m}$ to $100 \mathrm{~m}^{[11]}$, covering the hoisting range of the tower crane.

Besides, the Bluetooth wireless module provides a low-cost way for information exchange among mobile devices and provides connectivity of these devices to the Internet ${ }^{[21]}$. To complete the system operation, the smart tower crane needs to be connected by servers or handheld devices. Therefore, the Bluetooth module is preferred in the smart tower crane system.

\section{The digitized 3D site}

To establish a digitized three dimensional (3D) site with three mutually orthogonal axes is the first 
and foremost step for the SCO-based tower crane system. The purpose of digitizing the site is to assign each location within the site with three a unique trixial $(x, y, z)$ coordinate. $\mathrm{X}$-axis and $\mathrm{y}$-axis forms the plane that are parallel to the ground. Z-axis is parallel to the direction of gravity. Together, $\mathrm{x}$-axis, $\mathrm{y}$-axis and $\mathrm{z}$-axis form a 3D cubic grid that is large enough to contain the whole site and buildings to be erected. Therefore, anywhere on site including the temporary storage area, vehicle parking area, construction area and so on can be located by corresponding coordinates. Digitizing the whole construction site area is fundamental for SCOs to achieve location awareness. The coordinate system serves as the standard of site location information. After SCOs sense their real-time locations within the site, the information will be compiled in a $(x, y, z)$ format. When SCOs need to communicate the location information between each other or update location information back to database, the location information is also conveyed in the $(x, y, z)$ format.

The establishment of the digitized 3D site is based on site plans. The z-axis is set referring to elevation plans while $\mathrm{x}$-axis and $\mathrm{y}$-axis are set on site layout plans. Since the location tracking and route calculation are based on relative displacements, the base point $(0,0,0)$ can be set at the center or any angle of the cubic grid. The cubic grid is large enough to contain the irregular-shaped site. Each façade could be matched with a $\left(x^{\prime}, y^{\prime}\right)$ value as their destination location value in the designated installation location. For facades on ground level, the $z$ ' values are set as 0 . For facades on above levels, the $z$ ' values are set according to floor levels in elevation plans. If project has been designed with Building Information Modeling (BIM) models, the model can be directly matched with the 3D cubic grid so that each objects in the BIM model carries the matched $\left(x^{\prime}, y^{\prime}, z^{\prime}\right)$ value as destination locations.

\section{System operation flow}

As shown in Figure 1, the system block diagram specifically demonstrates the dynamic interactions among three elements of the SCO-based tower crane system, including the smart crane, smart prefabricated component and the information center.

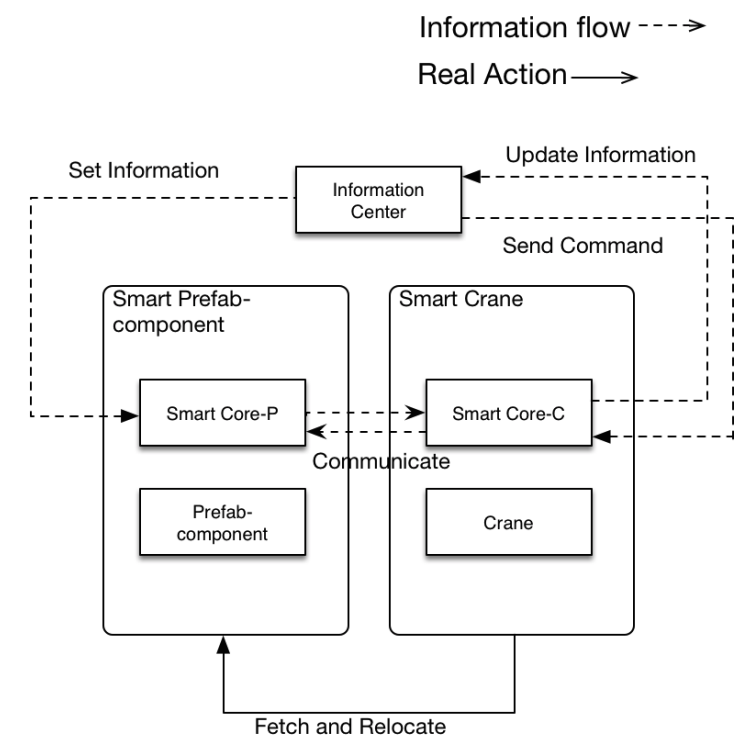

Figure 1. The block diagram of the smart crane tower system

The information center serves as a database to support the system, containing information of the digitized 3D site as well as information of designated installation locations for every 
prefabricated component. The destination location $\left(x^{\prime}, y^{\prime}, z^{\prime}\right)$ of each smart prefabricated component, which is extracted from 3D digitized site from the information center, will be firstly input into its smart unit during prefabrication process. Besides, the smart prefabricated component could also carry other information such as weight, height, and installation requirements. The database of the information center is shared by on-site servers and can be accessed by handheld devices.

When smart prefabricated components have been delivered on site, the smart crane will be triggered into operation mode by a command from servers in the site control center, or from handheld devices. A set of smart unit will also be augmented to the tower crane so that the smart tower crane could communicate with the smart prefabricated components and act autonomously. When smart prefabricated components enter into the temporary storage area, they are configured to the discoverable mode. Since each smart component carries a unique ID, the smart crane could identify each smart component by its ID.

The smart crane will then establish the communicative Bluetooth connection with smart components. After the smart tower crane validates the ID of the each component, the component would send back its current location $\left(x_{0}, y_{0}, z_{0}\right)$ and destination location $\left(x^{\prime}, y^{\prime}, z^{\prime}\right)$ to the crane. By using the current location $\left(x_{0}, y_{0}, z_{0}\right)$ and the destination location $\left(x^{\prime}, y^{\prime}, z^{\prime}\right)$, the crane is enabled to calculate the optimum route for fetching and relocating the target component by calculating the rotation degree of the jib, parallel moving distance of the trolley and vertical moving distance of the hook block.

Basically, there are three steps for the smart crane to reach the targeted components. First, the jib of the smart crane will rotate in a 360 degree plane that is parallel to the ground until pointing the targeted component. Second, the trolley will move forward or backward along the jib based on the parallel moving distance calculated. Finally, the crane will move the hook block up and down by adjusting the hoisting rope. Similarly, by reversing and repeating the above three steps, the crane could relocate the target component to the destination location after fetching it. During the fetching and relocating operation of the smart tower crane, the smart prefabricated component could sense the replacement of its location though awareness, which is achieved by the microcontroller and the location tracking module in the smart unit. The IMU could provide the real-time acceleration and rate of angular change. These data would then be converted into the 3D coordinate format as the real-time location $\left(x_{i}, y_{i}, z_{i}\right)$ by the microcontroller, which will be calibrated by the GPS outputs.

Once the real-time location $\left(x_{i}, y_{i}, z_{i}\right)$ matches destination location $\left(x^{\prime}, y^{\prime}, z^{\prime}\right)$, the smart prefabricate component would alert the smart tower crane, suggesting that the component is successfully arriving at the designated installation location. Afterwards, the smart crane will update current location $\left(x_{i}, y_{i}, z_{i}\right)$, which should be equal to the designated destination location $\left(x^{\prime}\right.$, $\left.y^{\prime}, z^{\prime}\right)$ theoretically, of the smart prefabricated component to the information center. At this time, the information of current location $\left(x_{i}, y_{i}, z_{i}\right)$ could be regarded as the as-built information of the smart fabricated component, which is potential for future use for the purpose of maintenance and facility management. The full process of the operation could also be demonstrated through the schematic diagram as Figure 2, Figure 3 and Figure 4. 


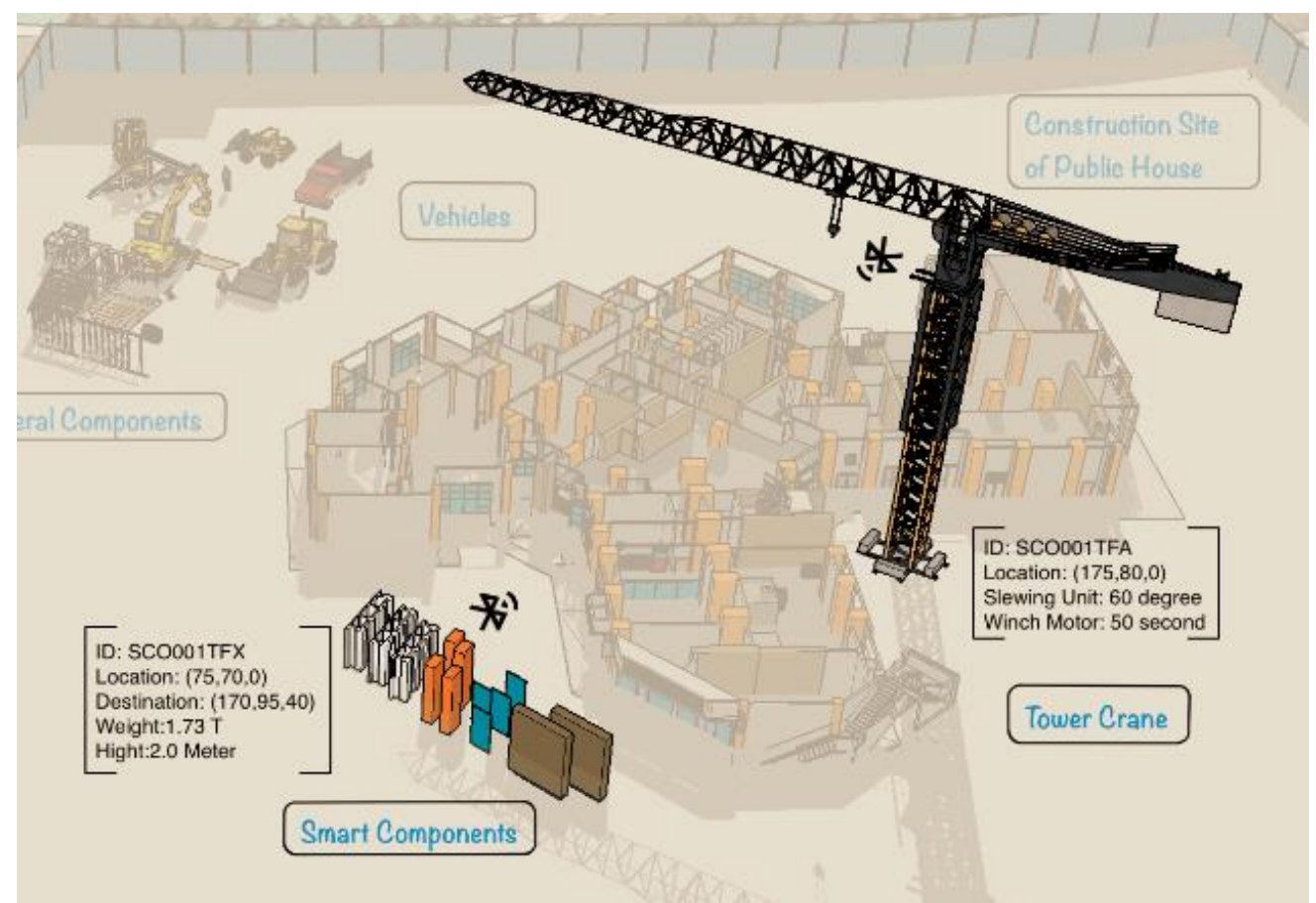

Figure 2. Communication establishment

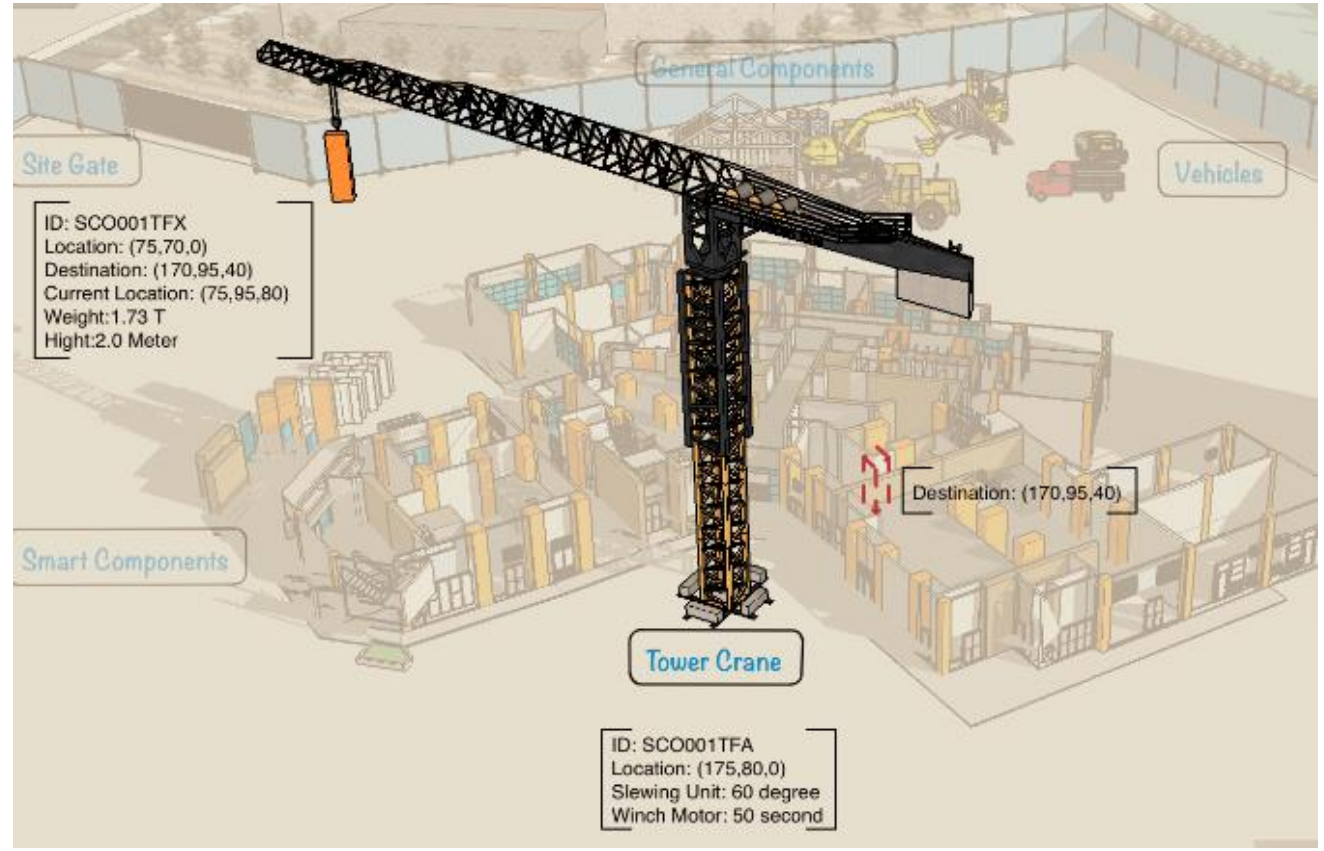

Figure 3. Autonomous installation 


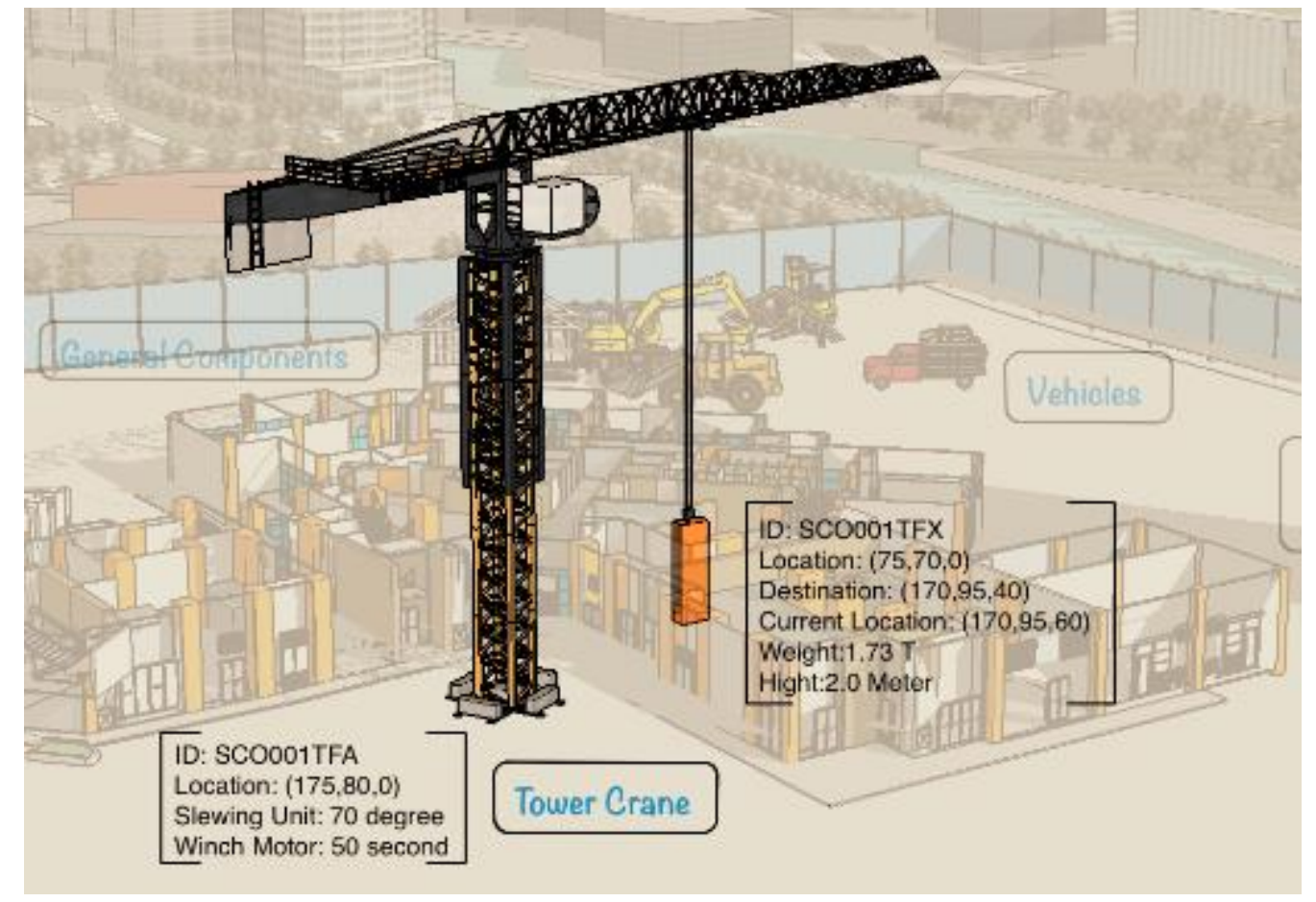

Figure 4. Destination confirmation

\section{Discussion}

The smart tower crane system is envisaged to improve the prefabrication construction by autonomous action-taking to free labor from site operations. The reduction in human involvement is potential to enable better safety control and to decrease human-centric interventions and possible errors. Besides, the object-to-object communicativeness presented by the smart tower crane and the smart prefabricated component lays the foundation towards Internet of Things in the construction industry.

As the smart tower crane system is being developed and tested in a pilot study in a prefabrication construction project in Hong Kong, the effectiveness and efficiency of this system is yet to be demonstrated. The empirical performance of the smart tower crane will be presented in future study. Besides, more construction objects including machines, equipment and on-site components are potential be augmented into SCOs under various circumstances to step towards a panoramic smart construction industry.

\section{Conclusion}

This paper presents the key concepts, technologies, and the framework for developing smart tower crane system for prefabrication construction. The fundamental concept underlying this study is the concept of smart construction objects (SCOs), which are construction objects that are augmented with sensing, communicating and autonomous abilities. A smart unit is embedded into the traditional tower crane and prefabricated components to make them into SCOs. To establish a reference location system, the construction site would be digitized with 3D cubic gridlines so that each location could be assigned with a unique coordinate. Based on the SCOs and location 
referring to the 3D digitized site, the on-site installations could be preceded autonomously by the smart tower crane system.

\section{Acknowledgement}

The work is supported by HKU Post Doctor Fellowship (PDF)/Research Assistant Professor (RAP) Scheme. Project title: BIM-and IoTs-oriented Smart Construction Objects (SCOs): The Elementary Particles of Future Construction.

\section{Reference:}

[1]Jaillon, L., \& Poon, C. S. (2009). The evolution of prefabricated residential building systems in Hong Kong: A review of the public and the private sector.Automation in Construction, 18(3), 239-248.

[2]Lu, W. (2013). Enhancing housing production in Hong Kong through BIMatizing offshore prefabrication. Building Journal, 12-15.

[3]Venables, T., Barlow, J. and Gann, D. (2004). Manufacturing Excellence: UK Capacity in Offsite Manufacturing, The Housing Forum, London.

[4]Chiang, Y. H., Chan, E. H. W. and Lok, L. K. L. (2006). Prefabrication and barriers to entry-a case study of public housing and institutional buildings in Hong Kong. Habitat International, (28), 1-18.

[5]Wong W. M. (2000). Prefabricated Construction in Hong Kong. Construction and Contract News. Issue No.3. Hong Kong

[6]Balaguer, C., Gambao, E., Barrientos, A., Puente, E. A., \& Aracil, R. (1996). Site assembly in construction industry by means of a large range advanced robot. In 13th International Symposium on Automation and Robotics in Construction, Tokyo (pp. 65-72). 65-72.

[7]Heintze, J., Teerhuis, P. C., \& Weiden, A. (1996). Controlled hydraulics for a direct drive brick laying robot. Automation in construction, 5(1), 23-29.

[8]Khoshnevis, B. (2004). Automated construction by contour crafting-related robotics and information technologies. Automation in construction, 13(1), 5-19.

[9]Balaguer, C., Abderrahim, M., Navarr, J. M., Boudjabeur, S., Aromaa, P., Kahkonen, K., ... \& Atkin, B. (2002). FutureHome: An integrated construction automation approach. Robotics \& Automation Magazine, IEEE, 9(1), 55-66.

[10]Niu Y., Lu W., Chen K, Huang G., and Anumba C., submitted to Journal of Computing in Civil Engineering

[11]Lu, M., Chen, W., Shen, X., Lam, H. C., \& Liu, J. (2007). Positioning and tracking construction vehicles in highly dense urban areas and building construction sites. Automation in Construction, 16(5), 647-656.

[12]Ochieng, W. Y., \& Sauer, K. (2002). Urban road transport navigation: performance of the 
global positioning system after selective availability.Transportation Research Part C: Emerging Technologies, 10(3), 171-187.

[13]Koruba, Z., and Tuśnio, J. (2009). A gyroscope-based system for locating a point source of low-frequency electromagnetic radiation. Journal of Theoretical and Applied Mechanics, 47(2), 343-362.

[14]Madgwick, S. O., Harrison, A. J., \& Vaidyanathan, R. (2011, June). Estimation of IMU and MARG orientation using a gradient descent algorithm. InRehabilitation Robotics (ICORR), 2011 IEEE International Conference on (pp. 1-7). IEEE.

[15]Titterton, D., \& Weston, J. L. (2004). Strapdown inertial navigation technology(Vol. 17). IET.

[16]Huang, C., Liao, Z., \& Zhao, L. (2010). Synergism of INS and PDR in self-contained pedestrian tracking with a miniature sensor module. Sensors Journal, IEEE, 10(8), 1349-1359.

[17]Hyun, D., Yang, H. S., Yuk, G. H., \& Park, H. S. (2009, April). A dead reckoning sensor system and a tracking algorithm for mobile robots. InMechatronics, 2009. ICM 2009. IEEE International Conference on (pp. 1-6). IEEE.

[18]Caprari, G., Balmer, P., Piguet, R., and Siegwart, R. (1998). The autonomous micro robot "alice": a platform for scientific and commercial applications. Paper presented at the Micromechatronics and Human Science, 1998. MHS'98. Proceedings of the 1998 International Symposium on.

[19]Crespi, A., Badertscher, A., Guignard, A., and Ijspeert, A. J. (2005). AmphiBot I: an amphibious snake-like robot. Robotics and Autonomous Systems, 50(4), 163-175.

[20]Gomez, C., Oller, J., \& Paradells, J. (2012). Overview and evaluation of bluetooth low energy: An emerging low-power wireless technology. Sensors, 12(9), 11734-11753.

[21]Bisdikian, C. (2001). An overview of the Bluetooth wireless technology. IEEE Commun Mag, 39(12), 86-94. 